\title{
The Review and Reflection of Chinese New Agricultural Subsidy System
}

\author{
Yuneng $\mathrm{Du}$ (Corresponding author) \\ School of Management, University of Science and Technology of China \\ No. 203,7 building, Wen yuan, Shu shan district, Hefei, China \\ E-mail: fbdjlove@hotmail.com \\ Bo Sun \\ Foreign Language Department, Hefei Normal University \\ No.508, 52 building, Xi yuan, Shu shan district, Hefei, China \\ E-mail: sun8506@163.com \\ Bing Fang \\ School of Management, University of Science and Technology of China \\ No.1001,13 building, Yue guiyuan, Gui xiangju, Wanghu city, Hefei,China \\ Tel: 86-852-6184-0093 E-mail: fbing@ustc.edu.cn
}

\begin{abstract}
In recent years, China has gradually cancelled agricultural tax which has been imposed for more than two thousand years. Reviewing and reflecting on the history, target, pattern, scope of the Chinese new agricultural subsidy system, this paper discusses the dilemma of subsidy target, irrational subsidy structure and environmental pollution. Finally the bottleneck of Chinese new agricultural subsidy system and its development direction are discussed.
\end{abstract}

Keywords: Agricultural economy, Subsidy policy, Environmental pollution

\section{Introduction}

Implementing agricultural subsidy represents agricultural development for a country. After abolishing the agricultural tax in 2003, China's agricultural system stepped into a new period which could be called Agricultural Adjustment Period (Yujiro Hayami, Yoshihisa Godo, 2003, P16-27). In 2004, the central government adopted a series of measures to support and benefit agriculture, rural areas and farmers, which was first mentioned in the "One document". China obviously showed its intention of agricultural support strategy. Like many developed countries, Chinese new agricultural subsidy system also encountered a lot of problems (Kym Anderson, Will Martin, Ernesto Valenzuela, 2006, P357-376). During the reform of China's agricultural system from 2003, some dilemmas arose such as food safety, farmers' income increase (Zhang Juwei, Wang Dewen, 2004, P1-13), executive inefficiency (David Orden 2007, P53-56), fuzzy subsidy target (Chen Yongfu, 2005, P4-8), etc. These papers point out some specific problems in Chinese new agricultural subsidy system. However, few scholars summarize and reflect on the problems of Chinese new agricultural subsidy system from a systematic perspective. With a time span from 2004 to 2009, by employing literature review and interviews, this paper summarizes and reflects on the history, target, pattern, scope and capital supply of Chinese new agricultural subsidy system. Finally, some suggestions about the Chinese new agricultural subsidy system are proposed.

\section{The history of China's agricultural subsidy policy}

The implementation of the reform and opening-up policy has greatly promoted farmers' income since 1978. Farmers' income has grown most rapidly from 1978 to 1984 . To be more specific, the growth rate per annum amounted up to 15.9 percent (Sheng Laiyun, 2005, P21-25). During this period, farmers' income increase is mainly attributed to the implementation of family contract responsibility system. Since the mid-1980s, the influence of system reform on farmers' income has become weak, and the income growth rate of agricultural family has been no longer as high as before. From 1984 to 1990, the annual per-capita income for farmers increased by only 4.2 percent. In the 1990s, the increase of non-agricultural income has become an important impetus in the farmers' income growth. After 1.8 percent growth rate in 1990 and 2 percent in 1991, farmers' income has increased rapidly for five successive years from 1993 to 1997. After 1997, the farmers' income growth rate began to fall, and farmers' income experienced a slow increase. It became very difficult to increase farmers' income further (Hu Jiang, 2008, P33-35). Meanwhile, China's output of food has been falling year by year, which has endangered China's food safety. At the beginning of the 21st century, these problems have become a formidable task for Chinese government. (Liang Shifu, Wang Yapeng, 2008, P1-5 Peng Teng,Ma Yuelong, 2009, P72-75). 
China's agricultural subsidy policy began in the late 1950s, formed and developed in the reform and opening-up period. However, the agricultural subsidy before 2004 was based on agricultural taxes and price scissors, so the meaning of the subsidy was not obvious (Justin Yifu, 2008, P258-259). It was not until 2004 when the agricultural tax was abolished that agricultural subsidy boasted more substantial meaning. Before 2003, China's agricultural subsidy mainly took the shape of price subsidy in circulation, but it was not efficient enough. According to the calculation, the efficiency of the price subsidy in developed countries is 25 percent, while the efficiency of the price subsidy in China is only 14 percent (Liang Shifu, 2005, P4-8). And huge subsidy spending didn't guarantee national food safety. In 2003, according to the experience of foreign food subsidy and international convention, food subsidy changed from indirect subsidy to direct subsidy, namely, in compliance with certain principles and standards, cash subsidy is directly given to farmers. Against the backdrop of food subsidy mode conversion, Anhui and Jilin provinces conducted the pilot study of direct food subsidy in 2002. And then in 2003, the pilot study has already covered 13 provinces. After that, in 2004, the No.1 file explicitly pointed out that China must establish direct subsidy policy for farmers in order to protect the interests of food farmers from 2004 and rescind the agricultural tax all over the country. Since 2004, Chinese new agricultural subsidy system has been established in the world largest agricultural country finally.

\section{The dilemma of Subsidy Target: The binary choice of production and income}

After the new agricultural subsidy system was established, Chinese theoretical circle started to discuss the location of new agriculture subsidy target and mainly focus on farmers' income and the national food safety. Some scholars consider that as a method of agricultural support, subsidy should take both farmers' income and the national food safety into account (Guo Chunli, Zhao Guojie, 2010, P91-93). While other scholars consider that because farmers' income increase and the national food safety is incompatible, the "Safety" and "Income" need to be separated (Zhao Deyu, Gu Haiying, 2004, P58-64). And this school is further divided into two groups, one valuing food safety and the other preferring farmers' income increase (Xiang Li, 2008, P44-48). Interpreting the 2004-2009 "No.1 document", we can find that the target of Chinese new agricultural subsidy system is to realize the strategic construction of supporting agriculture through food safety and farmers' income. In other words, the execution of Chinese new agricultural subsidy system gives consideration to both of the two targets, and the subsidy is extended to larger areas and varieties. But with the subsidy becoming more widespread, the effect of policy implementation becomes weak. Furthermore, the actual work efficiency is rather low due to different regional subsidy standards, high management cost and information asymmetry in such aspects as food planting, popularization of good strains of seeds and agricultural machinery.

With the expansion of subsidy, the subsidy covers most farmers and maintains at a low level. According to the author's investigation in rural areas of Anhui province, most farmers consider the subsidy as a kind of welfare to vulnerable groups, so they get confused with various kinds of subsidies. They tend to have a liking for the subsidy but they are not sensitive to it, so the stimulating effect on planting food is limited. Farmers are the subjects of agricultural production and operation; thus they are free to plant which kind of crop. On the one hand, family operation is an objective fact in Chinese agricultural production, and food production activities are primarily decided not by subsidy but by resource constraints, food price and production inertia. On the other hand, farmers are "reasonable people". When they decide to plant food or economic crops, they will consider the profit and subsidy. If the food subsidy does not suffice to offset the opportunity cost of food planting, farmers will not be motivated to plant foods. In addition, the local government pays more attention to economic crops in order to stimulate local economic development, so the local government is reluctant to promote food production (Cheng Youzhong, 2006, P2-6). Because agricultural technology cannot certainly increase food yield, farmers will try to produce more economic crops for more income, which would cause hidden danger of food safety. Consequently, with such a limited subsidy, most farmers are inclined to plant as before and plant what is needed, which could not ensure food safety effectively. As to increasing farmers' income, the limited stimulation is hard to achieve the aim of increasing both food yield and income. Moreover, the subsidy less than RMB 100 per mu is rather trivial under the background of farmers' diversified income sources.

The practice has shown that the aim of new agricultural subsidy system is not well achieved. The reason lies in ignoring the incompatibility between food safety and farmers' income increase. Within the framework of the new system, the realization of food security relies on subsidy which is meant to stimulate farmers' food production enthusiasm. But the fact that food demand elasticity is low while profit is not high determines the profit margin of food is relatively lower than that of economic crops and non-agricultural industries. Therefore, farmers' income is bound to be sacrificed due to limited resources. On the other hand, farmers' income increase makes it necessary to expand the range of subsidy and subsidize the production of various crops. As a result, the marginal effects of stimulation in gain production will decrease. The practice which values both food safety and farmers' income 
increase is not as effective as expected either.

\section{The low capita subsidy and irrational structure}

The capita subsidy is low. Recent years have witnessed the increase of direct income subsidy and other various kinds of protection and support in the United States, the European Union, Japan and other developed countries and regions (Xu Yuanming, 2008, P112-116). The total agricultural subsidy of the United States, the European Union and Japan in 2002 is as much as $\$ 300$ billion, which accounts for 80 percent of the total agricultural subsidy in the whole world. In 2009, Chinese government has allocated RMB 123 billion of direct subsidy for food producers, good strains of seeds and purchase of agricultural machinery and tools, but the subsidy is far from enough for 900 million farmers. In many areas, the capita subsidy is less than RMB 100 per year. What is more, a large part of farmers' subsidy income is offset by the increasing prices of means of agricultural production and raw materials. In a word, the effectiveness of subsidy is fairly weak.

The subsidy is irrational. Currently in China, various kinds of subsidies are involved in all the process of agricultural production and circulation. Due to its wide and scattered range, subsidy is low in each procedure. So the agricultural subsidy can not be effective. As for cotton subsidy, for example, high-quality varieties are not subsidized continuously and sufficiently. The leading enterprises devoting to industrialization of agriculture are still faced with insufficient financial support. Farmers' training only occupies a very small part of government service expenditure, which directly leads to the lack of farmers' human resources. At the same time, the popularization of agricultural technology subsidy is slow and inefficient. The government does not make it clear that marketing service will be subsidized, which brings about the lack of marketing service. Inspection service is hard to meet the need of domestic production, import and export because of insufficient subsidy and backward equipment. Natural disaster relief and environmental protection payments are also limited.

China's agricultural subsidy policy mainly involves finance, agriculture, foreign trade, food, civil affairs, bank and other departments, so the transaction cost is high (Guo Yanru, Liu Jing 2004, P43-46). In the mean time, due to the influence of selfish departmentalism, local protectionism and rent-seeking activities, the efficiency of agricultural subsidy is quite low. The problems are mainly as follows. Firstly, agricultural subsidy is between government and individuals, so the transaction cost is too high. Secondly, the subsidy standard is hard to calculate, so the operation cost is high. Thirdly, there is no special agency to take charge of the process of "Measurement of land $\rightarrow$ Application $\rightarrow$ Announcement $\rightarrow$ Re-check $\rightarrow$ Re-announcement" (Jiang Gaoming, 2008), thus it is rather difficult to coordinate so many departments involved and it brings a huge financial burden to the local government. Last but not least, direct food subsidy is calculated on the basis of the food area, but there is some inconsistency between the actual food area and the calculated area.

\section{Agricultural subsidy stimulates farmers to harm the environment}

From 2004 the Chinese government started to subsidize farmers when they buy means of agricultural production, especially the large agricultural machinery. The policy was very important in reducing agricultural production cost, increasing food farmers' income and promoting food production. From 2006 the Chinese government issued a fresh policy which was called agricultural material synthesis subsidy. This kind of subsidy was to offset the price inflation of diesel oil, chemical fertilizer and pesticide. This policy was implemented especially in major food-producing districts and counties. The subsidy standard generally did not exceed 30 percent of the price of agricultural implements, and the total subsidy for one machine did not exceed RMB 30,000 (adjusted to RMB 50,000 in 2009). Up to 2009 , subsidy has benefited all the farmers, agricultural machine-using companies and registered milk corporations, etc. The subsidy for agricultural machinery and tools has increased from 400 million in 2004 to 10 billion in 2009. But this policy is not good news to agricultural environmental protection (LI Chuan-jian, 2007, P33-35), because these subsidies stimulate farmers to use oil machines on the farm and increase the use of oil products like chemical fertilizers and pesticides. Although this "Oil Agriculture" can improve the efficiency and output of agricultural production, it pollutes the ecological environment and will influence safety and quality of farm products in the long term. For example, the carbon dioxide and carbon monoxide emitted from agricultural machines can do harm to climate and environment; wide and unreasonable use of fertilizers can easily bring excessive heavy metal content in agricultural products; fertilizers can also cause water pollution in the farm land; pesticides in use can bring about air pollution and endanger our environment and health. Moreover, pesticide residue can get into the human body through food chain, which threatens people's health.

\section{The bottleneck and development direction of Chinese new agricultural subsidy system}

According to the goal of China's agricultural subsidy system, China needs to establish a perfect mechanism to balance different benefits claims. But China's existing agricultural subsidy system is difficult to achieve this goal. The reasons are listed below. 
The source of interest is unitary and the WTO rules are not made full use of. Social entities, organizations and enterprises cannot be motivated to participate in agricultural subsidy system. Therefore, subsidy is afforded merely by national finance. Currently, Chinese agricultural expenditure is divided into so many different types that the limited funds cannot form a joint force (Xiaobo Zhang, 2006, P713-726). According to the statistics of Chinese Industrial Policies and Regulations Authority of the Ministry of Agriculture, Chinese agricultural subsidy expenditure with the character of "green box" policy accounts for a very small part of the gross agricultural output, while agricultural subsidy expenditure with the character of "yellow box" policy is only 1.23 percent (Fang Lingli, Wang Yapeng, 2005, P7-10). There is still enough room to dispense more subsidies since WTO rules require that the maximum subsidy rate should never be more than 8.5 percent. In the eleven kinds of WTO "green box policy", China only uses six of them (government general service expenditures, food safety, domestic food aid, natural disaster relief, ecological environment protection and regional development aid). As regards "green box policy", agricultural education, agricultural insurance, structure adjustment subsidy are absent in China's current agricultural policy system. But these subsidies are crucial to improve the agricultural comprehensive production capacity and increase farmers' income. As to "yellow box policy", due to the fact that agriculture has backed the industrial development for a long time, national macro policies are mainly devoted to industry and agricultural product consumers (Fan Yi 2006, P38-41). The government cannot give farmers price support. What is worse, the government takes away the benefit which should belong to the farmers by controlling the food price at a lower level than that in the international market. This has frustrated farmers to a certain extent (Wang Yan-fei, Zeng Guo-ping, 2006, P32-36). The "green box policy" and "yellow box policy" is not taken advantage of reasonably in Chinese new agricultural subsidy system. Chinese government attitude toward agricultural subsidy policy still needs to be transformed, and financial support needs to be further intensified. Finally, government should take active measures to increase subsidy sources and make full use of the "yellow box" and "green box" policy.

The benefit-distribution mechanism loses its balance. The current structure of Chinese agricultural subsidy is imbalanced and irrational, which causes unreasonable distribution of subsidy. Large quantities of subsidies in China are used to make up the differential between purchase and sales prices, lower the price of means of agricultural production and discount loans in circulation fields (Ren Dapeng, Guo Haixia, 2005, P7-9). Subsidies in such areas as agricultural education, agricultural technology popularization, agricultural infrastructure construction, adjustment of agricultural production structure and organization structure are rather meager, but these areas are essential to restructure the traditional agriculture and enhance agricultural development in the future. At the same time, the imperfect supervision mechanism also causes loss of funds, which is embodied by the lack of macro supervision in the subsidy funds. 30 percent of agricultural subsidy often cannot be obtained by farmers in time or even for ever. And part of the subsidy is used for other purposes (Wang Guohua, 2004, P1-3). From the micro perspective, there is a lack of agricultural subsidy budget, audit, and efficiency assessment management.

Finally, the benefit guarantee mechanism is absent. As an inferior, inefficient, high-risk industry, especially after China's entry into WTO which worsened the exterior environment, agricultural production is confronted with more natural and non-natural risks. Chinese agriculture is now facing unprecedented challenges. But in today's Chinese new agricultural subsidy system, the agricultural insurance system is still missing, thus the agricultural risk cannot be effectively avoided.

\section{The improving methods of China's new agricultural subsidy system}

Increase the agricultural subsidy. Agricultural subsidy is a kind of compensation for agriculture which is a inferior industry. Its purpose is to promote food output and farmers' income. If the subsidy is not enough, it's hard to achieve the purpose of increasing output and farmers' income. In recent years, China has made more efforts to increase agricultural subsidy. But compared with the level of economic development and the agricultural development, the subsidy is still inadequate. In order to achieve the purpose of agricultural subsidy policy, it's necessary to enhance the subsidy level so that farmers' income can be increased and the gap between urban and rural income can be bridged. Increasing the agricultural subsidy and implementing industry-repaying-agriculture policy is a strategic move for Chinese medium-term industrialization. At the present time, China has already become the second largest economic entity, and there is a lot of space to make use of in the "yellow box" and "green box" policies, so China can afford to support and protect agriculture.

Optimize agricultural subsidy structure. Firstly, a system with both regular and temporal subsidy needs to be established. The temporary subsidy should take the form of periodic subsidy in compliance with foreign experiences, while the regular subsidy needs to offset the rising of agricultural production costs and give farmers a stable expected income. Secondly, agricultural insurance system should be instituted. Agricultural insurance system can effectively avoid agricultural risk. Thirdly, the government ought to form agricultural ecological environment subsidy system and rural education subsidy system. These policies can protect and improve the agricultural planting 
structure, promote the efficiency of land output, and enhance the international competitiveness of agricultural products.

Perfect the way of agricultural subsidy. Firstly, indirect subsidy should be changed into direct subsidy. Currently, the subsidy benefit often suffers a loss before it is acquired by farmers. Therefore, as required by "green policy", the subsidy benefit should be transferred from circulation areas into production areas. Secondly, simplify the subsidy process. In recent years, more than 20 kinds of subsidies are distributed in China. And the subsidy standards (taxed area, contracted area, actual planting area) and the subsidy scope (subsidy for all the farmers, subsidy for special farmers) differ a lot in different regions, which creates confusion to a certain extent. So the subsidy standards and scope need to be uniformed and some similar subsidies (wheat, rice, rape, cotton) can be integrated. Thirdly, institutions liable for the subsidy need to be reduced. Because so many departments have been involved, the implementation cost is high. According to the author's investigation in rural areas of Anhui province, one town would spend at least RMB 20 thousand or even RMB 30 thousand dispensing subsidy per year. So, it is essential to reduce subsidy institutions in order to lower the cost.

Speed up the agricultural subsidy legislation. Agricultural subsidy policy is a long-term policy. In order to make the agricultural subsidy policy effective for a long time, the agricultural subsidy legal system should be established, the aim of which is to increase farmers' income by direct subsidy and guarantee food safety. In addition, agricultural subsidy law should conform to both Chinese national conditions and WTO rules.

\section{References}

Yujiro, Hayami, Yoshihisa Godo. (2003). Agricultural Economic Review, China Agricultural Press, 9, 16-27

Kym Anderson, Will Martin, Ernesto Valenzuela. (2006). The relative importance of global agricultural subsidy and market access, World Trade Review,10,357-376

Zhang, Juwei, Wang, Dewen.(2004). Changes of the Nature in the Problems of Farmer's Income: An Investigation of Farmer's Income Structure and Growth by Regions, China Rural Survey 1,1-13

David Orden. 2007). Agricultural producer support estimates for developing countries, International Food Policy Research Institute,pp:53-56

Chen, Yongfu. (2005). Possible Improvements in the Direct Subsidy Policy in the Background of Food Security, Issues in Agricultural Economy, 4, 4-8

Sheng, Laiyun.(2005). An Analysis on the Trend of Changes in Growth Pattern of Farmers' Income, Chinese Rural Economy,5, 21-25

$\mathrm{Hu}$, Jiang. (2008). Study on the Causes and Countermeasures of the Difficulties of Increasing Farmer's Income at Present, Journal of Anhui Agricultural Sciences,36, 15233-15235

Liang, Shifu,Wang, Yapeng.(2008).Evolution and Path Selection of Food Security Policy in China, Research of Agricultural Modernization, 1, 1-5

Peng Teng, Ma Yuelong. (2009).The Increasing Income Effect of China Agricultural Subsidy[J]Modern Economic Research, 6, 72-75

Justin Yifu Lin, Fang Cai, Zhou Li. (2008). The China miracle: development strategy and economic reform, The Chinese university press, third edition, pp, 258-259

Liang Shifu.(2005). Possible Improvements in the Direct Subsidy Policy in the Background of Food Security, Issues in Agricultural Economy, 4, 4-8

Guo, Chunli, Zhao, Guojie.(2010).Evaluation the Efficiency of Food Direct Subsidy Policy in China Based on Institutional Economics, Chinese Agricultural Mechanization,4, 91-93

Zhao, Deyu, Gu, Haiying.(2004). Regional Differences in Direct Subsidization to Grain Producers in China and the Reasons, Chinese Rural Economy, 8, 58-64.

Xiang, Li. (2008). Economic Analysis of Grain Direct Subsidy Policy under the Background of Food Security, Journal of Anhui Agricultural Sciences, 36.(29). 12944-12948.

Cheng, Youzhong. (2006). State And Farmer: Public Products Supply Role And Function Locating, Journal of Huazhong Normal University.(Humanities and Social Sciences) 3, 2-6.

$\mathrm{Xu}$, Yuanming. (2008). Grain Subsides in Developed Countries and Its Implications for China, Forum of World Economy \& Politics, 6, 112-116.

Guo, Yanru, Liu, Jing. (2004). Transaction Cost of China's Agricultural Support Policy after Its Entry to WTO, 
Journal of Shangdong Finance Institute, 4, 43-46.

Jiang,Gaoming. (2008). The Measurement of land is changed from "less and less" to the "more and more".http://news.sciencenet.cn/sbhtmlnews/200822204440851201811.html.(February 21. 2008).

LI, Chuan-jian. (2007). Analyzing the Reform of Agricultural Subsidy Policies in China from the Viewpoint of Sustainable Development System, Territory \& Natural Resources Study, 4, 33-35.

Xiaobo Zhang. (2006). Fiscal decentralization and political centralization in China: Implications for growth and inequality ,Journal of Comparative Economics, 34, 713-726.

Fang, Lingli, Wang, Yapeng. (2005). Comparative Analysis of Domestic and Foreign Agricultural Subsidy Policies and Suggestion, Journal of Huazhong Agricultural University.(Social Science Edition). 2, 7-10.

Fan, Yi. (2006). From "Agriculture Supporting Industry" to "Industry Supporting Agriculture" --Compare on the Path Lean of "Two Trends" both in China and Abroad, Academic Journal of Zongzhou, 3, 38-41.

Wang, Yan-fei, Zeng Guo-ping. (2006). Agricultural Export and Farmers' Income: Empirical Analysis Based on the Causality, International Busines, 4, 32-36.

Ren, Dapeng, Guo Haixia.(2005). A Study of Legal System of Agricultural Subsidy in China, Rural Economy, 10,7-9.

Wang, Guohua. (2004). The Research about Supply of Rural Public Goods and Farmers' income Questions, Journal of cental university of finance \& economics, 1, 1-3. 